\title{
Tooth bending stress analysis of high speed curve face gear of composite transmission
}

\author{
Yongquan Yu, Chao Lin ${ }^{*}$, and Yanan $\mathrm{Hu}$ \\ State Key Laboratory of Mechanical Transmission in Chongqing University, No.174, Shazheng Street, Shapingba District 400044, \\ Chongqing, PR China
}

Received: 31 December 2020 / Accepted: 3 March 2021

\begin{abstract}
To promote the engineering application of composite transmission of high speed curve face gear, which consists of a cylindrical gear and a high speed curve face gear, the analysis of tooth bending stress should be taken into consideration. High speed curve face gear pair is a new type of curve face gear pair. Combined with the principle of high speed cam and curve face gear pair transmission, it can transfer the axial/rotation composite motion and power between two intersecting shafts. Based on the gear engagement principle, the gear meshing coordinate system was established and the fundamental of the high speed composite transmission was expounded. Combined with the tooth profile equation of generating gear, the tooth surface equation of high speed curve face gear was gained. Tooth force, contact ratio and normal load distribution were calculated. Then the tooth bending stress of high speed curve face gear during the transmission was calculated and analyzed in detail. Influence of basic parameters on tooth bending stress was discussed. Finally, the simulation and measurement experiment of tooth bending stress was carried out. By the comparison analysis of simulation, experiment and theory, the correctness of tooth bending stress calculation method was verified, which has important guiding significance for the further research of high speed curve face gear of composite transmission.
\end{abstract}

Keywords: Composite motion / curve face gear / high speed / normal load distribution / tooth bending stress

\section{Introduction}

Rotation and axial movement composite motion is highly applied in, for instance, agricultural machinery, textile machine, light industry machine, cleaning agencies and tool changing mechanism [1].

Common organizations that can realize rotation and axial composite motion are curve face gear pair, noncircular gear, and combination mechanisms, which contain linking rod and cam combination mechanisms [2], camlinkage combination mechanisms [3], gear-cam combination mechanisms [4], gear-linkage combination mechanisms and hydraulic-gear combination mechanisms [5]. Curve face gear pair is barely applicable for slow speed situations, while high speed curve face gear pair, combined with the characteristics of high speed and axial/rotational composite motion, can be used to special occasions.

Composite motion gear pair is a simple but special structure in composite motion organizations. It realizes the axial/rotation composite motion by changing the shape of

\footnotetext{
* e-mail: linchao@cqu.edu.cn
}

gear pitch curve. Composite motion gear pair is composed of non-circular gear rack motion pair, composite motion non-circular gear pair [6], orthogonal composite motion bevel gear pair [7], face gear pair and orthogonal curve face gear pair [8].

Curve face gear pair is a type of gear pair between two intersecting shafts. It incorporates the transmissions characteristics of face gear and non circular bevel gear. It is able to transfer motion and power with variable transmission ratio. Litvin et al. [9-11] researched the basic theory and application of face gear, for instance, design method, stress analysis and processing method.

High speed curve face gear pair is founded on curve face gear [12]. Combining the characteristics of curve face gear and cam organization, it achieves high speed composite motion through changing the gear pitch curve, and can take over many ordinary combination organizations. This is significant for simplifying mechanical structure and equipment lightweighting. Compared with ordinary combination organizations, this gear pair has superiority in greater functionality and uncomplicated structure, while this mechanism is currently not easy to design and manufacture. 
At present, the calculation method for the tooth bending stress is mainly composed of three methods: 30-degree tangent method, Lewis cantilever beam method [13] and finite element method [14]. The main methods for measuring tooth root bending stress are electrical measurement $[15,16]$ and photoelastic method [17]. Chen et al. [18] research the geometric design, meshing simulation, and stress analysis of pure rolling rack and pinion mechanisms. Gobski et al. [19-23] studied the worm wheel toothing accuracy, deformation, modification and diagnosis of gear meshing process in detail, which is of great significance to improve the performance of gear transmission.

The study on curve face gear pair is comparatively full and accurate, but the study on high speed curve face gear pair of composite motion is comparatively scarce. There are still some aspects to be studied, such as tooth surface resolution, tooth stress calculation and application.

In this paper, basic composite transmission principle of high speed curve face gear pair was analyzed, and tooth surface equation of high speed curve face gear was deduced. The tooth force, contact ratio and normal load distribution were analyzed. Combined with the cantilever plate method, tooth bending stress during the meshing process was calculated, and effects of basic parameters on tooth bending stress were analyzed. Finally, simulation and experimental measurement was carried out. Theoretical analysis results, simulation analysis results and experimental results were compared and analyzed. The correctness of theoretical calculation method was verified, which laid the foundation for following design and application.

\section{Composite transmission principle}

\subsection{Analysis of composite motion mechanism}

As shown in Figure 1, high speed curve face gear pair is able to achieve rotational/axial composite motion with variable transmission ratio. Cylindrical gear is the driving gear and high speed curve face gear is the driven gear.

Based on the kinematic relationship, composite motion principle of gear pair was analyzed, as shown in Figure 2. The gear pair is engaged in position $\mathrm{A}$ and position $\mathrm{B}$ respectively, and the the engaging points are $P_{1}$ and $P_{2}$ respectively. $O_{1}-x_{1} y_{1} z_{1}$ and $O_{f}-x_{f} y_{f} z_{f}$ are accompanied coordinate system and fixed coordinate system of pinion, respectively. $\mathrm{O}_{2}-x_{2} y_{2} z_{2}$ and $O_{m}-x_{m} y_{m} z_{m}$ are accompanied coordinate system and fixed coordinate system of high speed curve face gear, respectively. $r$ is the radius of pinion pitch curve. $\boldsymbol{r}_{\mathbf{2}}\left(\theta_{2}\right)$ and $R$ are the position vectors and the projection radius of the pitch curve of high speed curve face gear, respectively. When the gear pair changes from meshing position A to meshing position $\mathrm{B}$, the angular displacement of pinion is $\theta_{1}$, the angular displacement of high speed curve face gear is $\theta_{2}$ and $s\left(\theta_{2}\right)$ is the axial displacement of high speed curve face gear. $\omega_{1}$ and $\omega_{2}$ are are the angular speeds of the two gears respectively. $\boldsymbol{v}_{\mathbf{1}}$ and $\boldsymbol{v}_{2}$ are the absolute velocity of meshing point on the pitch curve of pinion and the absolute velocity of meshing point on the pitch curve of high speed curve face gear,

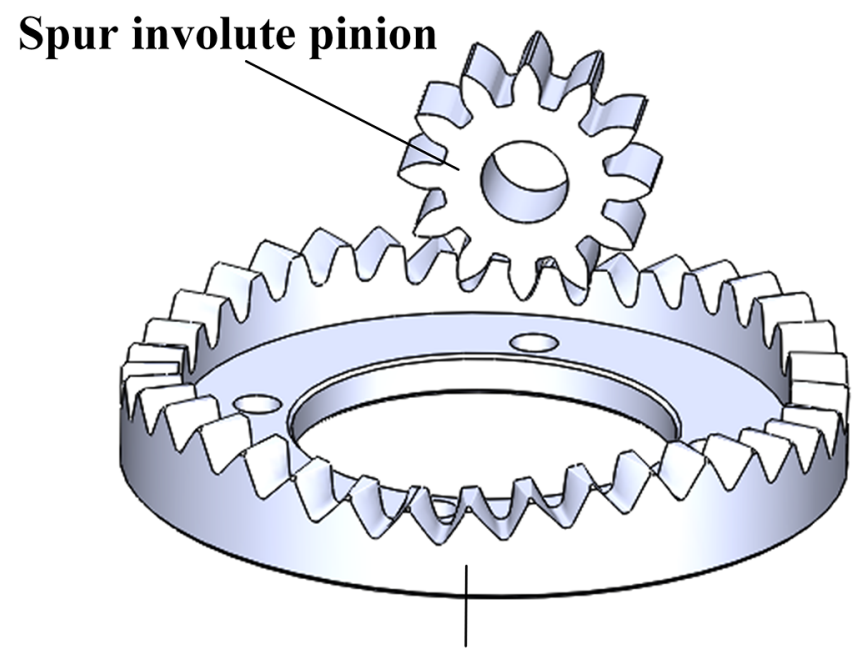

High speed curve face gear

Fig. 1. High speed curve face gear pair.

respectively. $\boldsymbol{v}_{\boldsymbol{s} \mathbf{2}}$ and $\boldsymbol{v}_{\boldsymbol{t} \mathbf{2}}$ are axial velocity and circumferential velocity of high speed curve face gear respectively. $\boldsymbol{n}$ is the normal vector for the meshing point.

In accordance with the space coordinate transform theory, the conversion matrix from $O_{1}-x_{1} y_{1} z_{1}$ to $O_{2}-x_{2} y_{2} z_{2}$ is

$$
\begin{aligned}
& \boldsymbol{M}_{21}=\boldsymbol{M}_{2 m} \boldsymbol{M}_{m f} \boldsymbol{M}_{f 1} \\
& =\left[\begin{array}{cccc}
-\sin \theta_{1} \sin \theta_{2} & \cos \theta_{1} \sin \theta_{2} & \cos \theta_{2} & -R \cos \theta_{2} \\
-\cos \theta_{2} \sin \theta_{1} & \cos \theta_{1} \cos \theta_{2} & -\sin \theta_{2} & R \sin \theta_{2} \\
-\cos \theta_{1} & -\sin \theta_{1} & 0 & r+s\left(\theta_{2}\right) \\
0 & 0 & 0 & 1
\end{array}\right]
\end{aligned}
$$

The coordinats of point $P_{1}$ in $O_{1}-x_{1} y_{1} z_{1}$ can be expressed as $\left[r \cos \theta_{1}, r \sin \theta_{1}, 0,1\right]^{T}$, then the coordinates of point $P_{2}$ in $\mathrm{O}_{2}-x_{2} y_{2} z_{2}$ is

$$
\boldsymbol{r}_{2}\left(\theta_{2}\right)=\left[-R \cos \theta_{2}, R \sin \theta_{2}, s\left(\theta_{2}\right), 1\right]^{T}
$$

Then the parametric equation of the pitch curve of high speed curve face gear can be expressed as

$$
\left\{\begin{array}{l}
x_{P_{2}}=-R \cos \theta_{2} \\
y_{P_{2}}=R \sin \theta_{2} \\
z_{P_{2}}=s\left(\theta_{2}\right)
\end{array}\right.
$$

As can be known from the equation (3), the pitch curve of the driven gear is a cylindrical curve, taking $R$ as the radius. Whenever pinion rotates at a certain angle, high speed curve face gear can realize composite motion of axial movement and rotation at the same time, and various composite motion can come true combined with the change of $s\left(\theta_{2}\right)$.

The $3 / 4 / 5$ order polynomial curve was taken as the pitch curve of high speed curve face gear and the axial 


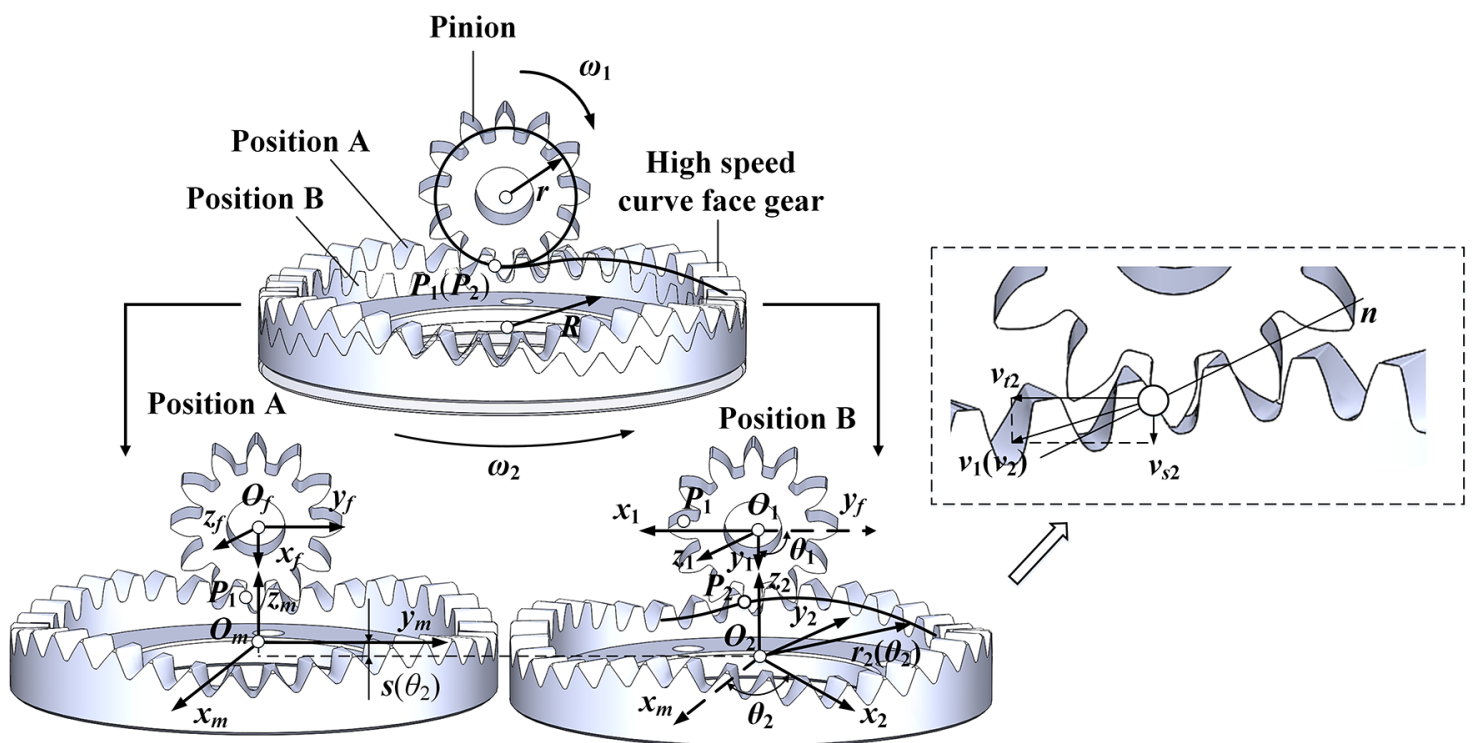

Fig. 2. Composite motion principle of gear pair.

displacement equation can be expressed as

\section{See equation (4) below.}

where, $n_{2}$ is the cycle number of pitch curve of curve face gear, $\theta_{h}=\pi / n_{2}$ is angular displacement from trough to peak, $h$ is maximum axial displacement.

Combined with Figure 2, the pinion pitch curve is purely rolling against the pitch curve of bull gear, so the arc length between the two meshing points on the pinion pitch curve is equal to the arc length between the two meshing points on the pitch curve of curve face gear.

$$
\overparen{P_{1} P_{2}}=r \theta_{1}=\int_{0}^{\theta_{2}} \sqrt{R^{2}+\left[s^{\prime}\left(\theta_{2}\right)\right]^{2}} d \theta_{2}
$$

where, $s^{\prime}\left(\theta_{2}\right)$ is the first derivative of $s\left(\theta_{2}\right)$ respect to $\theta_{2}$.

According to the gear engagement principle, the relationship between $\boldsymbol{v}_{\mathbf{1}}$ and $\boldsymbol{v}_{\mathbf{2}}$ can be expressed as

$$
v_{1}-v_{2}=0
$$

where, $\left|\boldsymbol{v}_{1}\right|=r \omega_{1}$ and $\left|\boldsymbol{v}_{2}\right|=\sqrt{R^{2} \omega_{2}^{2}+s^{\prime}\left(\theta_{2}\right)^{2} \omega_{2}^{2}}$.

Combined with equations (5) and (6), the composite transmission ratio of high speed curve face gear pair can be obtained as

$$
i_{12}=\frac{1}{r} \sqrt{s^{\prime}\left(\theta_{2}\right)^{2}+R^{2}}
$$

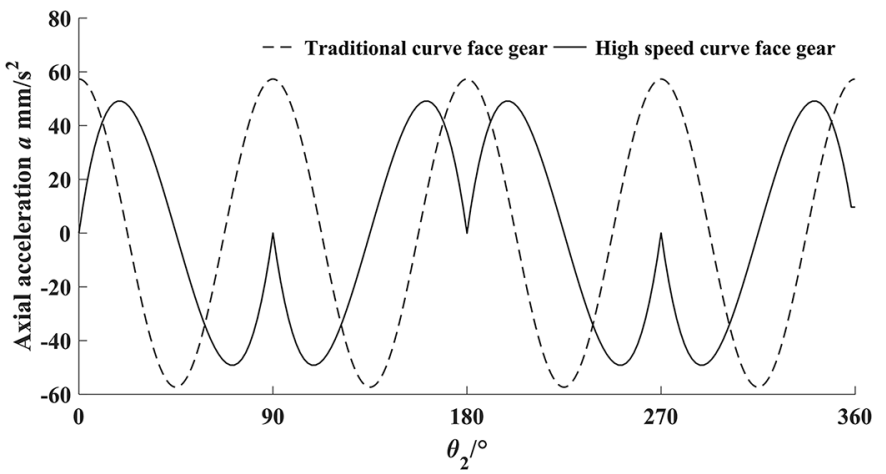

Fig. 3. Acceleration comparison.

The axial acceleration of high speed curve face gear is

$$
a_{s}=\frac{d^{2} s\left(\theta_{2}\right)}{d t^{2}}
$$

The acceleration variation of the traditional curve face gear and high speed curve face gear are shown in Figure 3.

For the traditional curve face gear of composite transmission, the maximum axial acceleration is larger than that of high speed curve face gear. Meanwhile, high speed curve face gear has no sudden change both in acceleration and speed during the whole movement, refraining from flexible impact and rigid impact, so this gear pair is available for high speed situations.

$$
s\left(\theta_{2}\right)=\left\{\begin{array}{l}
h\left(\frac{10}{\theta_{h}^{3}} \theta_{2}^{3}-\frac{15}{\theta_{h}^{4}} \theta_{2}^{4}+\frac{6}{\theta_{h}^{5}} \theta_{2}^{5}\right), 0 \leq \theta \leq \theta_{h} \\
h-h\left[\frac{10}{\theta_{h}^{3}}\left(\theta-\theta_{h}\right)^{3}-\frac{15}{\theta_{h}^{4}}\left(\theta-\theta_{h}\right)^{4}+\frac{6}{\theta_{h}^{5}}\left(\theta-\theta_{h}\right)^{5}\right], \theta_{h} \leq \theta \leq \Phi
\end{array}\right.
$$




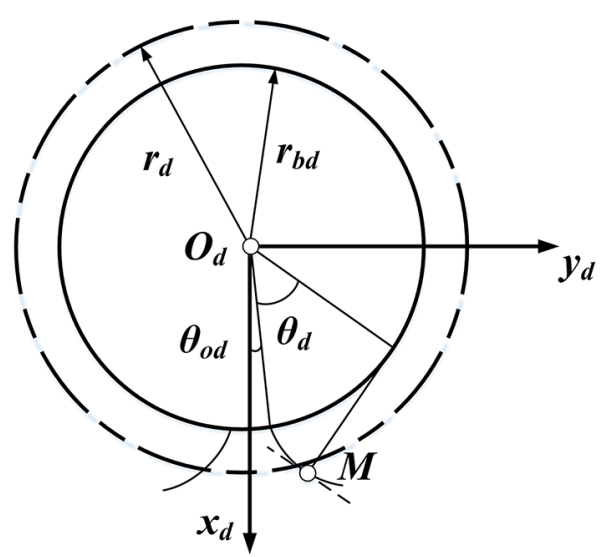

Fig. 4. Tooth profile of generating gear.

\subsection{Tooth surface equation of high speed curve face gear}

The tooth surface equation of high speed curve face gear can be obtained from the principle of conjugate tooth profile. The tooth profile of generating gear is shown in Figure $4 . r_{d}$ is the pitch radius.

Due to the symmetry of the tooth profile, the left tooth profile was discussed only, and the other side can be symmetrically obtained. The left tooth profile can be expressed in the accompanied coordinate system $O_{d}-x_{d} y_{d} z_{d}$ as

$$
\boldsymbol{r}_{d}\left(u_{d}, \theta_{d}\right)=\left[\begin{array}{c}
r_{b d}\left[\cos \left(\theta_{d}+\theta_{o d}\right)+\theta_{d} \sin \left(\theta_{d}+\theta_{o d}\right)\right] \\
r_{b d}\left[\sin \left(\theta_{d}+\theta_{o d}\right)-\theta_{d} \cos \left(\theta_{d}+\theta_{o d}\right)\right] \\
u_{d} \\
1
\end{array}\right]
$$

where, $u_{d}$ is a parameter to mark the tooth profile $\sum_{d}$ of generating gear in the direction of $z_{d} \cdot\left(u_{d}, \theta_{d}\right)$ is the Gauss coordinate of $\sum_{d} . r_{b d}=r_{d} \cos \alpha_{0}$ is the base radius. $\theta_{\text {od }}=\pi /\left(2 Z_{d}\right)-i n v \alpha_{0}\left(i n v \alpha_{0}=\tan \alpha_{0}-\alpha_{0}\right)$ determines the cogging width on the base circle of generating gear. $Z_{d}$ is the teeth number of generating gear, $\alpha_{0}$ is the profile angle of generating gear.

Combined with equation (1), the tooth profile $\sum_{2}$ of high speed curve face gear can be expressed in coordinate system 2 as

$$
\boldsymbol{r}_{2}\left(u_{d}, \theta_{d}, \theta_{1}\right)=\boldsymbol{M}_{2 d} \boldsymbol{r}_{d}\left(u_{d}, \theta_{d}\right)
$$

where, $\boldsymbol{M}_{2 d}$ can be obtained by changing $\theta_{1}$ to $\theta_{d}$ in $\boldsymbol{M}_{21}$.

The unit normal vector of tooth surface $\sum_{d}$ can be expressed in the coordinate system $O_{d}-x_{d} y_{d} z_{d}$ as

$$
\boldsymbol{n}_{d}^{(d)}=\frac{\frac{\partial \boldsymbol{r}_{d}}{\partial \theta_{d}} \times \frac{\partial \boldsymbol{r}_{d}}{\partial u_{d}}}{\left|\frac{\partial \boldsymbol{r}_{d}}{\partial \theta_{d}} \times \frac{\partial \boldsymbol{r}_{d}}{\partial u_{d}}\right|}=\left[\begin{array}{c}
\sin \left(\theta_{d}+\theta_{o d}\right) \\
-\cos \left(\theta_{d}+\theta_{o d}\right) \\
0
\end{array}\right]
$$

Pitch curve of high speed curve face gear

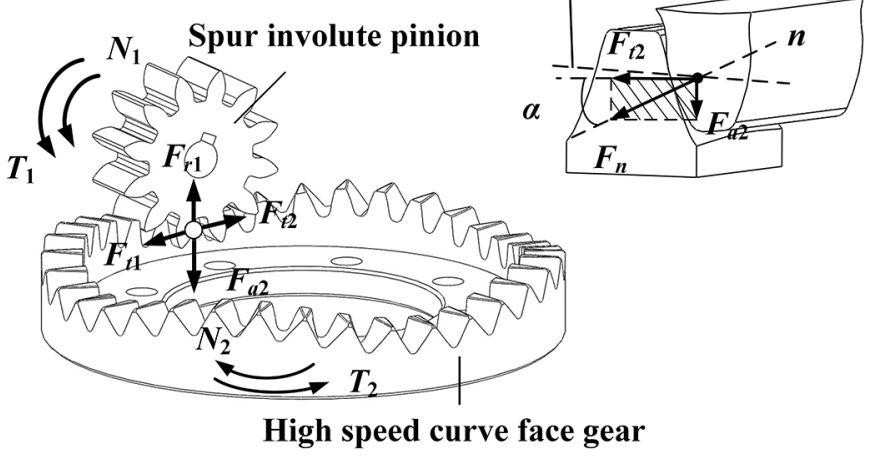

Fig. 5. Normal force of gear tooth.

The meshing equation between generating gear and high speed curve face gear can be expressed as

$$
f\left(u_{d}, \theta_{d}, \theta_{1}\right)=\boldsymbol{N}_{d}^{(d)} \bullet \boldsymbol{v}_{d}^{(d 2)}=\boldsymbol{n}_{d}^{(d)} \bullet \boldsymbol{v}_{d}^{(d 2)}=0
$$

where, $\boldsymbol{N}_{d}^{(d)}$, which is the same direction as $\boldsymbol{n}_{d}^{(d)}$, is the normal vector of the tooth surface $\sum_{d}$ in coordinate system $O_{d}-x_{d} y_{d} z_{d}, \boldsymbol{v}_{d}^{(d 2)}=\left(\boldsymbol{\omega}_{d}^{(d)}-\boldsymbol{\omega}_{2}^{(d)}\right) \times \boldsymbol{r}_{d}\left(u_{d}, \theta_{d}\right)$ is the relative velocity between $\sum_{d}$ and $\sum_{2}$ in the coordinate system $O_{d}-x_{d} y_{d} z_{d}, \omega_{d}^{(d)}$ is the angular velocity vector of generating gear in the coordinate system $O_{d}-x_{d} y_{d} z_{d}, \omega_{2}^{(d)}$ is the angular velocity vector of high speed curve face gear in the coordinate system $O_{d}-x_{d} y_{d} z_{d}$.

According to the gear engagement principle, the tooth surface equation of high speed curve face gear can be expressed as

$$
\left\{\begin{array}{l}
\boldsymbol{r}_{2}\left(u_{d}, \theta_{d}, \theta_{1}\right)=\boldsymbol{M}_{2 d} \boldsymbol{r}_{d}\left(u_{d}, \theta_{d}\right) \\
f\left(u_{d}, \theta_{d}, \theta_{1}\right)=0
\end{array}\right.
$$

where, $\theta_{1}=\frac{1}{r} \int_{0}^{\theta_{2}} \sqrt{R^{2}+\left[s^{\prime}\left(\theta_{2}\right)\right]^{2}} d \theta_{2}$.

Elimination of $u_{d}$, the tooth surface equation of high speed curve face gear can be expressed by $\boldsymbol{r}_{2}\left(\theta_{d}, \theta_{1}\right)$.

\section{Tooth bending stress analysis}

\subsection{Force analysis}

\subsubsection{Normal force of gear tooth}

In theory, there are only component forces in two directions. For high speed curve face gear, there exist just axial force and tangential force, without radial force. The force analysis is shown in Figure 5.

$T_{1}$ and $T_{2}$ are the torque of pinion and high speed curve face gear respectively. $N_{1}$ and $N_{2}$ are the rotational speed of pinion and high speed curve face gear respectively. $F_{n}$ is the normal force. $F_{t 1}$ and $F_{r 1}$ are the tangential force and the radial force of pinion, respectively. $F_{t 2}$ and $F_{a 2}$ are the tangential force and the axial force of high speed curve face gear, respectively. 
Thus the tangential force $F_{t 1}$ can be obtained as

$$
F_{t 1}\left(h, r, n_{2}, N_{1}, T_{2}\right)=T_{1} / r=\left(T_{2}+I_{2} \beta_{2}\right) /\left(r i_{12}\right)
$$

where, for the high speed curve face gear, $I_{2} \approx M_{2} R^{2}$ is the moment of inertia, $M_{2}$ is the mass, and $\beta_{2}$ is the angular acceleration.

Combined with equation (7), the tooth force can be expressed as

$$
\begin{gathered}
F_{t 1}\left(h, r, n_{2}, N_{1}, T_{2}\right) \\
=\frac{T_{2}}{\sqrt{R^{2}+s^{\prime}\left(\theta_{2}\right)^{2}}}-\frac{r^{2} \omega_{1}^{2} s^{\prime}\left(\theta_{2}\right) s^{\prime \prime}\left(\theta_{2}\right)}{\left(R^{2}+s^{\prime}\left(\theta_{2}\right)^{2}\right)^{3 / 2}} M_{2} R^{2} \\
F_{t 2}\left(h, r, n_{2}, N_{1}, T_{2}\right)=-F_{t 1}\left(h, r, n_{2}, N_{1}, T_{2}\right) \\
F_{r 1}\left(h, r, n_{2}, N_{1}, T_{2}, \alpha\right)=F_{t 1}\left(h, r, n_{2}, N_{1}, T_{2}\right) \tan \alpha \\
F_{a 2}\left(h, r, n_{2}, N_{1}, T_{2}, \alpha\right)=-F_{t 1}\left(h, r, n_{2}, N_{1}, T_{2}\right) \tan \alpha \\
F_{n}\left(h, r, n_{2}, N_{1}, T_{2}\right)=\frac{F_{t 2}\left(h, r, n_{2}, N_{1}, T_{2}\right)}{\cos \alpha}
\end{gathered}
$$

where, $s^{\prime \prime}\left(\theta_{2}\right)$ is the second derivative of $s\left(\theta_{2}\right)$ relative to $\theta_{2}$. $\alpha$ is the pressure angle of gear pair.

\subsubsection{Contact ratio}

The calculation and analysis of contact ratio has a significant impact on both load distribution and tooth bending stress analysis of high speed curve face gear composite transmission. The contact ratio of gear pair is shown in Figure 6. $n$ is the meshing line, $\overline{B_{1} B_{2}}$ is the actual meshing segment and $P_{n}$ is the normal pitch of high speed curve face gear. The instantaneous contact ratio of gear pair can be expressed as follows

$$
\varepsilon\left(\theta_{2}\right)=\overline{B_{1} B_{2}} / P_{n}
$$

To simplify the calculation, the gear pair is expanded according to the gear-rack on the plane as shown in Figure 7.

$O_{C}-x_{C} y_{C}$ is the expansion coordinate system of pitch curve of high speed curve face gear on the plane, $O_{p 1}-x_{p 1} y_{p 1}$ and $O_{p 2}-x_{p 2} y_{p 2}$ are the fixed coordinate system and the accompanied coordinate system of pinion pitch curve respectively. $n$ is the meshing line, $\overline{B_{1} B_{2}}$ is the actual meshing segment, and $P$ is the meshing point. $l$ is the tangent line of the two pitch curves, and $\alpha_{0}$ is profile angle of pinion. $\alpha_{1}$ is the tilt angle of the pitch curve of high speed

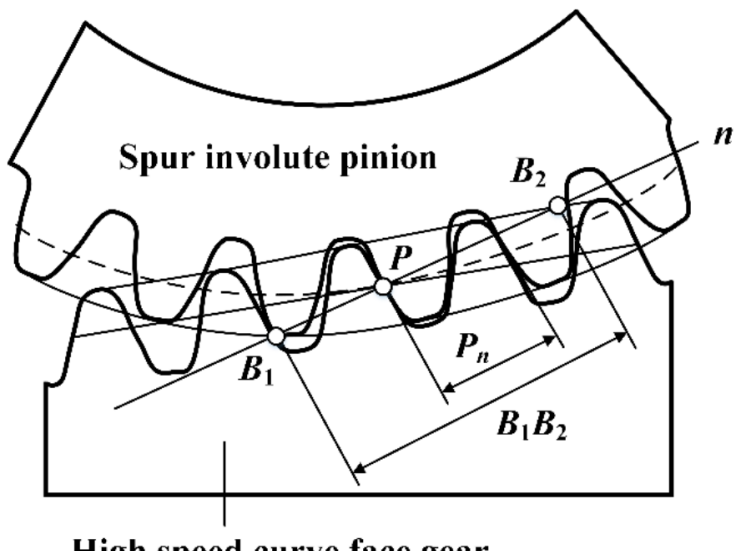

High speed curve face gear

Fig. 6. Contact ratio of high speed curve face gear pair.
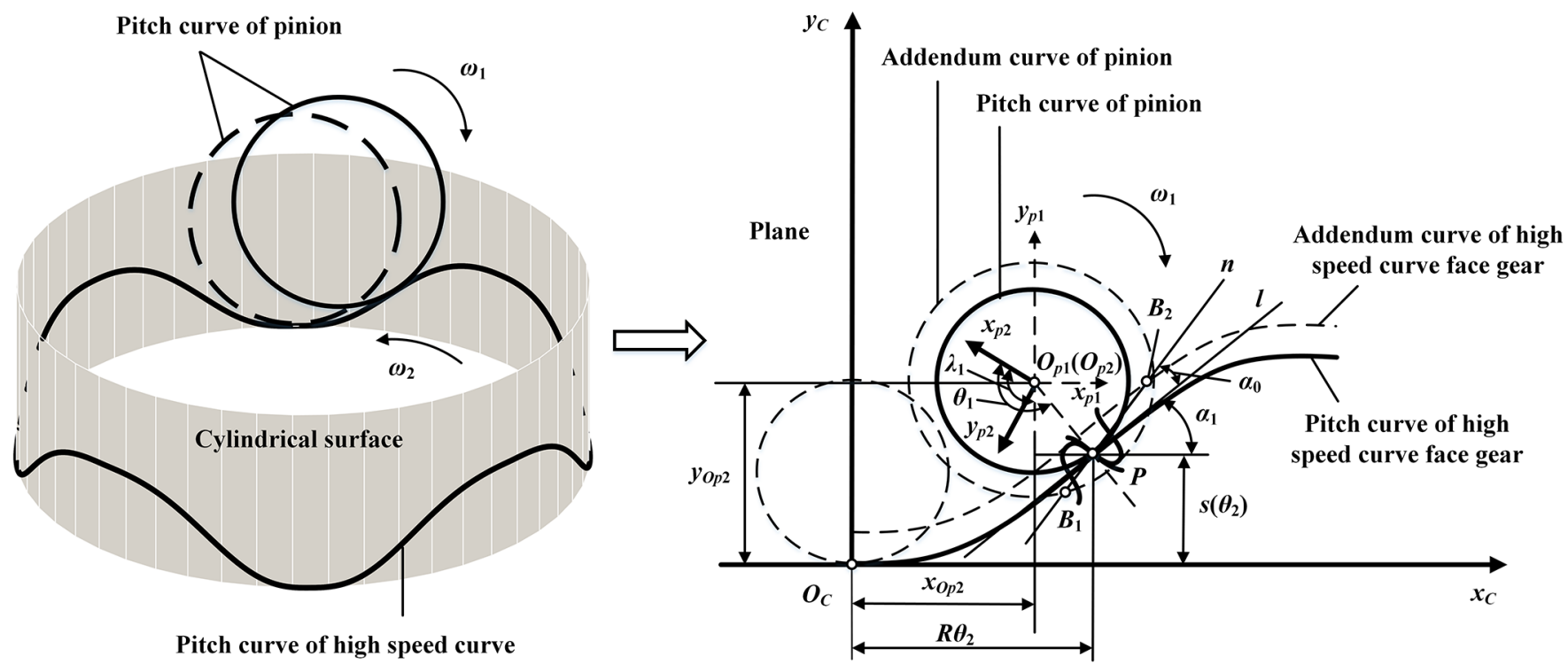

Pitch curve of high speed curve face gear

Fig. 7. Calculation of instantaneous contact ratio. 
curve face gear in $O_{C}-x_{C} y_{C} \cdot\left(x_{O p 2}, y_{O p 2}\right)$ is the coordinate of point $O p_{1}\left(O p_{2}\right)$ in coordinate system $O_{C}-x_{C} y_{C} \cdot \theta_{1}$ is the rotation angle of pinion and $\theta_{2}$ is the pitch curve parameter of high speed curve face gear.

The coordinate of meshing point $P$ in coordinate system $O_{C}-x_{C} y_{C}$ is $\left[R \theta_{2}, s\left(\theta_{2}\right), 1\right]^{T}$, then the equation of meshing line $n$ can be expressed in the coordinate system $O_{C}-x_{C} y_{C}$ as

$$
y_{n}=\tan \left(\alpha_{0}+\alpha_{1}\right)\left(x_{n}-R \theta_{2}\right)+s\left(\theta_{2}\right)
$$

The expanded pitch curve of high speed curve face gear can be expressed in the coordinate system $O_{C}-x_{C} y_{C}$ as

$$
\left\{\begin{array}{l}
x_{C}=R \theta_{2} \\
y_{C}=s\left(\theta_{2}\right)
\end{array}\right.
$$

The expanded addendum curve of high speed curve face gear can be expressed in the coordinate system $O_{C^{-}} x_{C} y_{C}$ as

$$
\left\{\begin{array}{l}
x_{h a 2}=R \theta_{2}-h_{a} \sin \alpha_{1} \\
y_{h a 2}=s\left(\theta_{2}\right)+h_{a} \cos \alpha_{1}
\end{array}\right.
$$

where, $h_{a}$ is the addendum height of pinion and high speed curve face gear.

The homogeneous conversion matrix from $O_{p 2^{-}} x_{p 2} y_{p 2}$ to $O_{C}-x_{C} y_{C}$ can be obtained as

$$
M_{O_{C} O_{p 2}}=\left[\begin{array}{ccc}
-\sin \lambda_{1} & \cos \lambda_{1} & R \theta_{2}-r \sin \alpha_{1} \\
-\cos \lambda_{1} & -\sin \lambda_{1} & s\left(\theta_{2}\right)+r \cos \alpha_{1} \\
0 & 0 & 1
\end{array}\right]
$$

where, $\lambda_{1}=\theta_{1}-\alpha_{1}$.

The addendum curve of pinion can be expressed in coordinate system $O_{p 2}-x_{p 2} y_{p 2}$ as

$$
r_{2}^{h_{a 1}}=\left[\left(r+h_{a}\right) \cos \theta,\left(r+h_{a}\right) \sin \theta, 1\right]^{T}
$$

where, $\theta \in[0,2 \pi]$.

Then addendum curve of pinion can be obtained in the coordinate system $O_{C}-x_{C} y_{C}$ as

$$
r^{h_{a 1}}=\left[\begin{array}{c}
\left(r+h_{a}\right) \sin \left(\theta-\lambda_{1}\right)+R \theta_{2}-r \sin \alpha_{1} \\
-\left(r+h_{a}\right) \cos \left(\theta-\lambda_{1}\right)+s\left(\theta_{2}\right)+r \cos \alpha_{1} \\
1
\end{array}\right]
$$

The intersection point $B_{1}\left(x_{B 1}, y_{B 1}\right)$ between line $n$ and the addendum curve of pinion can be obtained as

$$
\left\{\begin{array}{l}
x_{h a 2}=\left(r+h_{a}\right) \sin \left(\theta-\lambda_{1}\right)+R \theta_{2}-r \sin \alpha_{1} \\
y_{h a 2}=-\left(r+h_{a}\right) \cos \left(\theta-\lambda_{1}\right)+s+r \cos \alpha_{1} \\
y_{n}=\tan \left(\alpha_{0}+\alpha_{1}\right)\left(x_{n}-R \theta_{2}\right)+s\left(\theta_{2}\right)
\end{array}\right.
$$

The intersection point $B_{2}\left(x_{B 2}, y_{B 2}\right)$ between line $n$ and the addendum curve of high speed curve face gear can be obtained as

$$
\left\{\begin{array}{l}
x_{h a 2}=R \theta_{2}-h_{a} \sin \alpha_{1} \\
y_{h a 2}=s\left(\theta_{2}\right)+h_{a} \cos \alpha_{1} \\
y_{n}=\tan \left(\alpha_{0}+\alpha_{1}\right)\left(x_{n}-R \theta_{2}\right)+s\left(\theta_{2}\right)
\end{array}\right.
$$

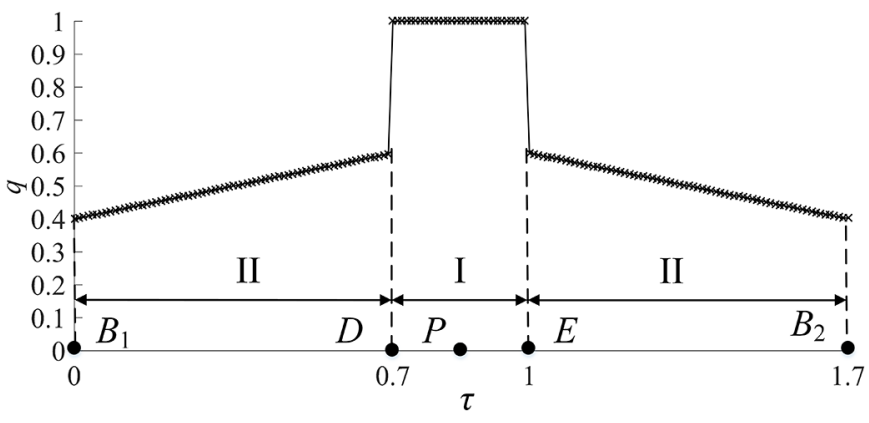

Fig. 8. Normal load distribution.

where, $\left(x_{n}, y_{n}\right)$ is the coordinate of point on the meshing line $n$ in coordinate system $O_{C}-x_{C} y_{C}$

The instantaneous contact ratio of high speed curve face gear pair can be obtained as

$$
\varepsilon\left(\theta_{2}\right)=\frac{\overline{B_{1} B_{2}}}{P_{n}}=\frac{\sqrt{\left(x_{B 2}-x_{B 1}\right)^{2}+\left(y_{B 2}-y_{B 1}\right)^{2}}}{\pi m \cos \alpha_{0}}
$$

\subsubsection{Normal load distribution}

In the process of high speed curve face gear composite transmission, in order to maintain the continuity of motion and power, the actual contact ratio of the gear pair must be greater than 1, that is, there are multiple pairs of gear teeth engaging at the same time. At this point, the normal load must be distributed between the teeth engaged simultaneously, and the normal load distribution is shown in Figure 8.

According to equation (29), in this instant, the contact ratio is 1.7. $q$ is the load distribution coefficient and $\tau$ is the meshing line. The high speed curve face gear pair is engaged at point $P$. $B_{1}$ is the actual meshing starting point, $B_{2}$ is the actual meshing endpoint, $D$ is the starting point of single teeth-meshing and $E$ is the endpoint of single teethmeshing. I is the double teeth-meshing area and II is the single teeth-meshing area. In the double teeth-meshing area, the load distribution coefficient increases gradually from 0.4 to 0.6 , and then decreases from 0.6 to 0.4 . In the single teeth-meshing area, the load distribution coefficient is 1 . Combined with the load distribution coefficient, the meshing force of single tooth in the meshing process can be obtained.

\subsection{Tooth bending stress analysis of high speed curve face gear}

\subsubsection{Calculation and analysis of tooth bending stress}

The shape of the tooth surface of high speed curve face gear is relatively complicated. With the different position of the tooth width direction, the boundary contour curves of each section of tooth perpendicular to the tooth width are also different. The tooth bending stress can be solved by cantilever plate method. The cantilever plate method regards the gear tooth as the cantilever plate and the cantilever plate as numerous cantilever bars of the same 

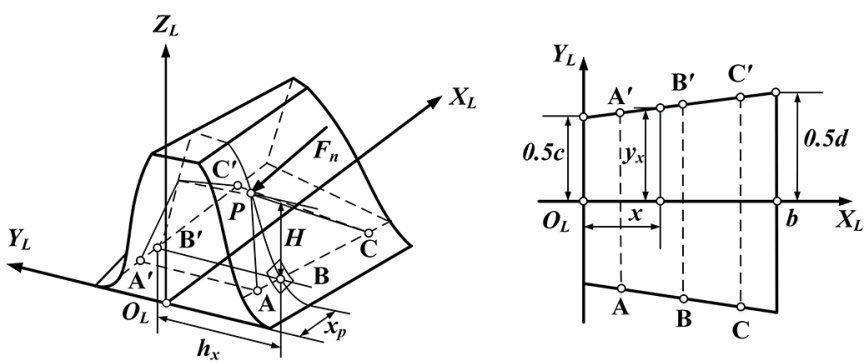

Fig. 9. Calculation model of tooth bending stress.

size. Saint-Venant principle can be applied to every single cantilever bar. The stress distribution along the tooth width can be approximately calculated by the cantilever plate model, but the tooth root section of high speed curve face gear is different from that of the cantilever plate model.

The cantilever model of high speed curve face gear is shown in Figure 9, and the tooth root section of high speed curve face gear can be approximated to an isosceles trapezium.

Assuming the tooth width is $b$, the inner width of tooth root section is $c$, and the outer width of tooth root section is $d$, the equation of tooth root section can be simplified as

$$
y_{x}= \pm\left(\frac{d-c}{2 b} x+\frac{c}{2}\right)
$$

The thickness of tooth root can be expressed as

$$
h_{x}=\frac{(d-c)}{b} x+c
$$

The contact point of tooth surface is $P$, the distance between $P$ and inner end is $x p$ and the distance between $P$ and tooth root section is $H$. The cantilever model of high speed curve face gear was equivalent to an infinite number of cantilever bars with a width of $\Delta(\Delta \rightarrow 0)$. The free ends of these rods are connected to the meshing point $P$ and the other end is fixed to the root section, as shown in Figure 9. Assuming that the fixed end of the cantilever $X$ is at a distance $x$ from the origin, then the distance between the fixed end of $X$ and point $P$ can be expressed as

$$
l_{x}=\sqrt{H^{2}+\left(x-x_{p}\right)^{2}}
$$

The axial component force and the tangential component force on the contact point of the driven gear cause compressive stress and bending stress at the root. Ignoring the effect of compressive stress, only bending stress was considered. The component of the meshing force in the direction perpendicular to the symmetry plane of the tooth is $F_{t 2}\left(\theta_{2}\right)$, and the force of the $\operatorname{rod} X$ is $F_{x}\left(\theta_{2}\right)$, which creates a bending moment $M_{x}$ at the root of the cantilever rod.

According to the material mechanics, the maximum bending tensile stress of the $\operatorname{rod} X$ in the cross section perpendicular to the length of the rod can be expressed as

$$
\sigma=\frac{M_{x} y_{x}}{I_{x}}=\frac{3 E \omega_{P} y_{x}}{l_{x}^{2}}
$$

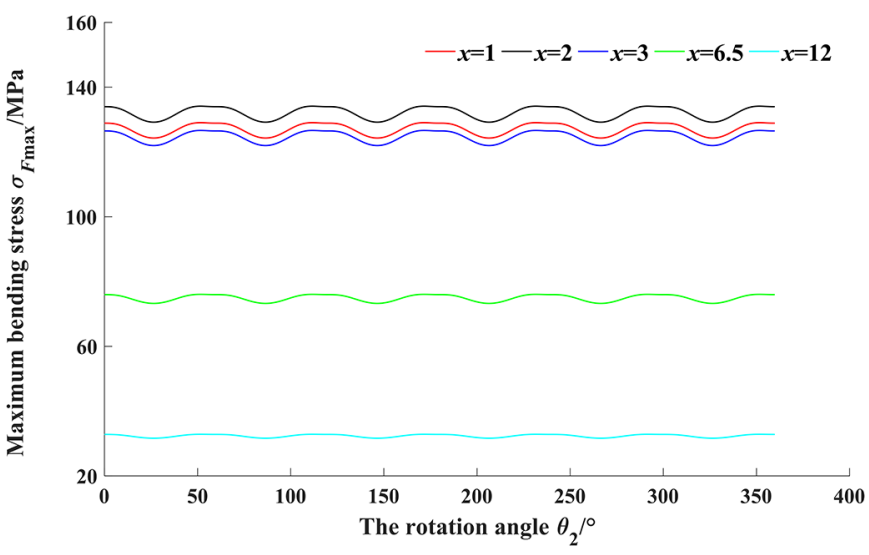

Fig. 10. Tooth root bending stress of different cross sections.

where, $M_{x}=3 E I_{x} \omega_{P} / l_{x}^{2}$ is the bending moment generated by the root of the cantilever $\operatorname{rod} X, E$ is the modulus of elasticity, $I_{x}=h_{x}^{3} \Delta / 12$ is the moment of inertia produced by the cross section of cantilever rod on the neutral axis, $\omega_{P}=F_{x}\left(\theta_{2}\right) l_{x}^{3} /\left(3 E I_{x}\right)$ is the deflection of point $P$.

Combined with equations (29)-(32), the tooth bending stress along the tooth width direction can be obtained as

$$
\sigma_{x}=\frac{3 E H \omega_{p}\left(\frac{d-c}{2 b} x+\frac{c}{2}\right)}{\left[H^{2}+\left(x-x_{p}\right)^{2}\right]^{3 / 2}}
$$

The stress at $x=a$ was taken as a reference value, then

$$
\sigma_{a}=\frac{6 b^{2} M_{x}\left[(d-c) x_{p}+b c\right]}{H^{3}} / \int_{0}^{b} \frac{[(d-c) x+b c]^{3}}{\left[H^{2}+\left(x-x_{p}\right)^{2}\right]^{3 / 2}} d x
$$

Combined with equations (33) and (34), $\sigma_{x}$ can be expressed as

$$
\sigma_{x}=\frac{6 b^{2} M_{x}[(d-c) x+b c]}{\left[H^{2}+\left(x-x_{p}\right)^{2}\right]^{3 / 2}} / \int_{0}^{b} \frac{[(d-c) x+b c]^{3}}{\left[H^{2}+\left(x-x_{p}\right)^{2}\right]^{3 / 2}} d x
$$

In the following analysis, the moduli of two gears are $4 \mathrm{~mm}$, the teeth numbers of pinion and high speed curve face gear are 18 and 27 respectively, and the profile angle of pinion is $20^{\circ}$. Assuming $x=1,2,3,6.5,12(\mathrm{~mm})$, the curve of the maximum tooth root bending stress of high speed curve face gear with the rotation angle $\theta_{2}$ can be drawn, as shown in Figure 10. The curve of $x=2 \mathrm{~mm}$ is the maximum tooth root bending stress curve of the corresponding section of the contact point.

- due to the periodicity of high speed curve face gear pair transmission, the maximum tooth root bending stress of each section also exhibits periodic changes, and the change period is the same; 


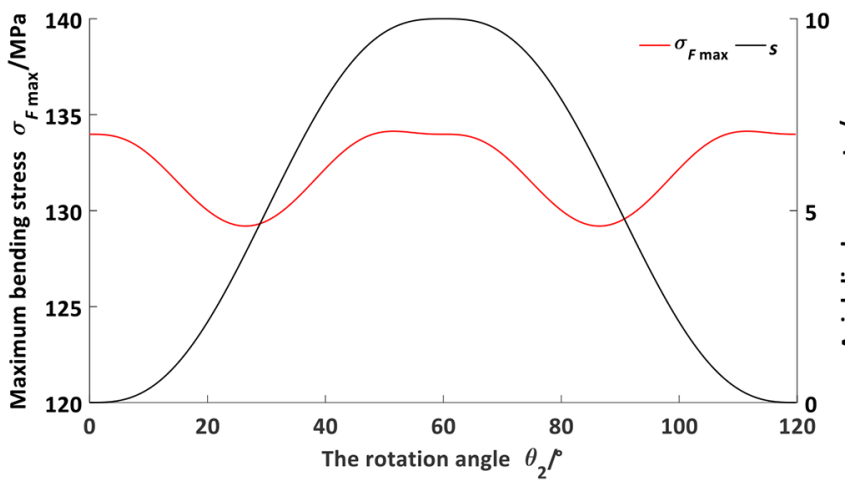

Fig. 11. Tooth root bending stress of $x=2 \mathrm{~mm}$.

Table 1. Parameter selection.

\begin{tabular}{llll}
\hline Type & $h / \mathrm{mm}$ & $n_{2}$ & $N_{1} / \mathrm{rpm}$ \\
\hline$\sigma_{F \max }$ & $6,8,(10)$ & $1,2,(3)$ & $(1000), 1500,2000$ \\
$s$ & $6,8,(10)$ & $1,2,(3)$ & $(1000), 1500,2000$ \\
\hline
\end{tabular}

- In the direction of the tooth width, as the distance from the section to the contact point increases, the stress value gradually decreases. When the tooth width of the driven gear is large enough, the stress value approaches zero;

- Due to the smaller tooth thickness of high speed curve face gear near the side of the swivel axis, the stress value around the contact point near the inner diameter side is larger than the outer diameter side. Therefore, in the design stage, the possibility of breakage of the tooth on the inner diameter side of high speed curve face gear should be taken into consideration.

Taking section $x=2 \mathrm{~mm}$ as an example, the variation of the maximum tooth root bending stress of high speed curve face gear in one cycle was analyzed as shown in Figure 11.

The load torque is $T_{2}=100 \mathrm{~N} \cdot \mathrm{m}$ and the input rotation speed is $1500 \mathrm{rpm}$. The maximum bending stress of high speed curve face gear changes two cycles within one meshing cycle. When $\theta_{2}$ changes from 0 to $60^{\circ}$, the displacement of high speed curve face gear is gradually increased from 0 to the maximum of $10 \mathrm{~mm}$. The maximum tooth root bending stress reduces from 134 to $129.3 \mathrm{MPa}$, then changes to slightly greater than the initial value, and finally returns to $134 \mathrm{MPa}$. When $\theta_{2}$ changes from 0 to $60^{\circ}$, the displacement of high speed curve face gear is gradually decreased from $10 \mathrm{~mm}$ to 0 , and the variation of tooth bending stress is the same as before.

\subsubsection{Influence of basic structural parameters on the tooth bending stress}

Different from the traditional gear transmission, for the curve face gear of composite transmission, the speed over $1000 \mathrm{rpm}$ can be called high speed. To investigate the influence of different structural parameters on the tooth bending stress, a single variable method was taken. The parameter selection is shown in Table 1.

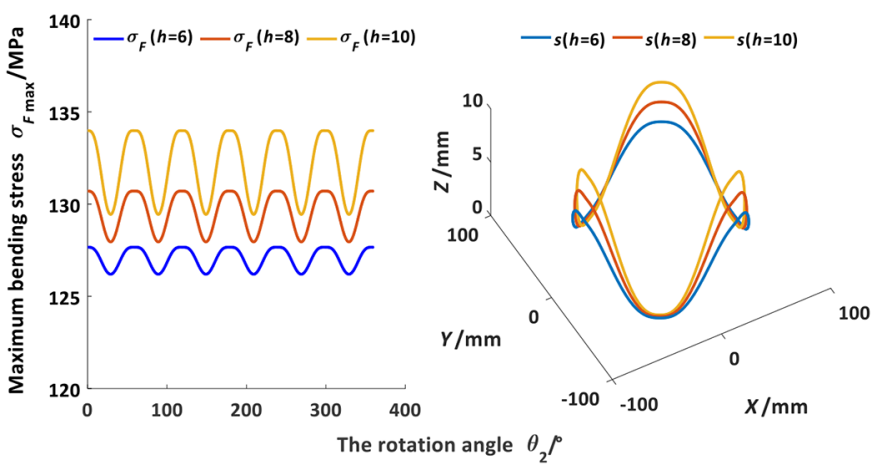

Fig. 12. Influence of $h$ on $\sigma_{F}$ and $s$.

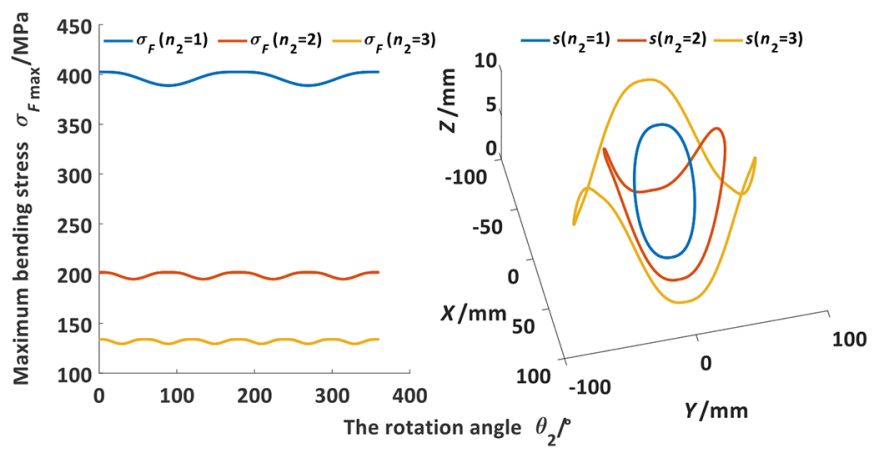

Fig. 13. Influence of $n_{2}$ on $\sigma_{F}$ and $s$.

In Table $1, h$ is the displacement amplitude, $n_{2}$ is the order of high speed curve face gear and $N_{1}$ is the rotation speed of pinion. $s$ is the axial displacement of high speed curve face gear. $\sigma_{F \max }$ is the maximum tooth bending stress of high speed curve face gear. The value in parentheses is the selected value when it is not a variable itself. Taking the corresponding section of $x=2 \mathrm{~mm}$ as the research target, the effect of parameters on tooth bending stress is as follows.

The variation of $\sigma_{F}$ and $s$ with $h=6,8,10 \mathrm{~mm}$ is shown in Figure 12.

With the increase of $h, s$ and $\sigma_{F}$ both increases, and neither period has changed. The variation amplitude of $\sigma_{F}$ increases, resulting in an increase in the impact load on the tooth of high speed curve face gear. Therefore, the appropriate $h$ should be choosed to reduce the bending stress and the impact load of gear teeth, so as to avoid the occurrence of tooth breaking.

The variation of $\sigma_{F}$ and $s$ with $n_{2}=1,2,3$ is shown in Figure 13.

With the increase of $n_{2}$, the periods of both $\sigma_{F}$ and $s$ are reduced. The maximum value of $s$ remains the same, while the maximum value of $\sigma_{F}$ decreases. And the impact load on the high speed curve face gear tooth is reduced. Therefore, $n_{2}$ can be appropriately increased to reduce the bending stress and impact load of the gear tooth, thereby avoiding the tooth breaking.

When $N_{1}=1000,1500,2000(\mathrm{rpm})$, the variation of $\sigma_{F}$ and $s$ is shown in Figure 14.

With the obvious increase of $N_{1}$, there is no change in $s$. The amplitude of $\sigma_{F}$ changes little and the period does not change, which indicates the gear tooth is subjected to a steady load and there is no sharp impact on the tooth. 


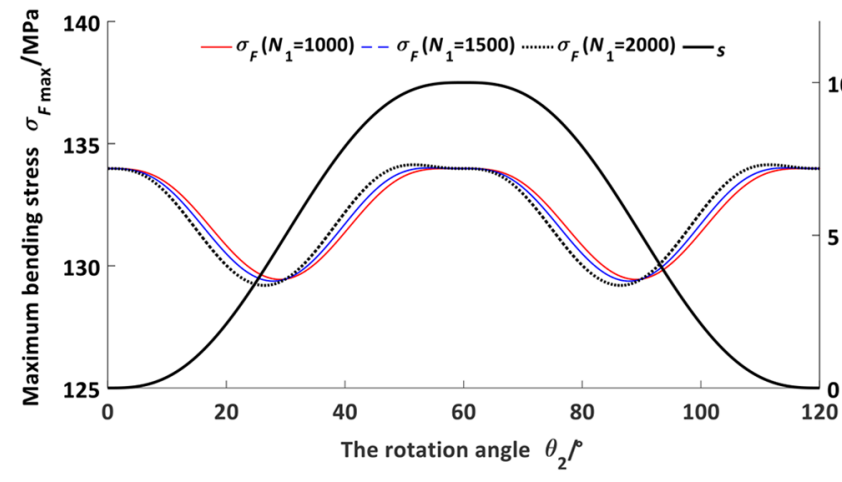

Fig. 14. Influence of $N_{1}$ on $\sigma_{F}$ and $s$.
Table 2. Main parameters of high speed curve face gear.

\begin{tabular}{llll}
\hline$h / \mathrm{mm}$ & $n_{2}$ & Modulus & Teeth number \\
\hline 10 & 3 & $4 \mathrm{~mm}$ & 27 \\
\hline
\end{tabular}

Table 3. Properties of high speed curve face gear.

\begin{tabular}{lll}
\hline Name & Material & Cutting method \\
\hline $\begin{array}{l}\text { High speed curve } \\
\text { face gear }\end{array}$ & $20 \mathrm{CrMnTi}$ & $\begin{array}{l}5 \text {-axis CNC } \\
\text { milling }\end{array}$ \\
\hline
\end{tabular}
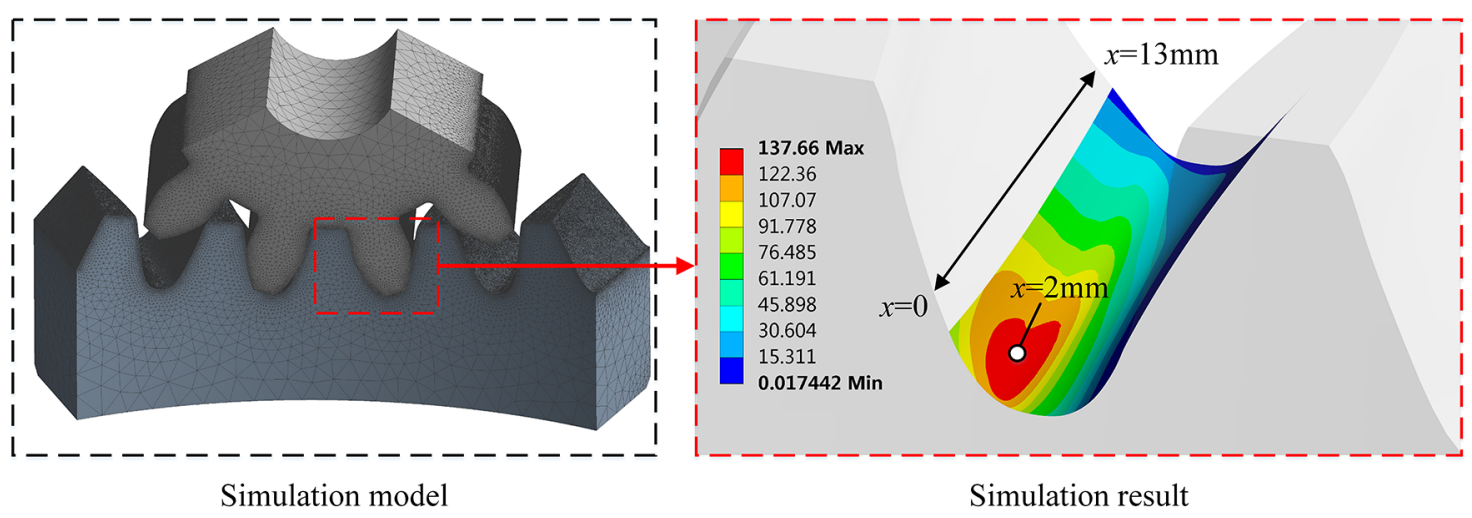

Fig. 15. Simulation of tooth root bending stress.

Meanwhile, the bending stress value is within a reasonable range, which will not cause tooth bending fatigue fracture. So the strong vibration and the tooth breaking will not happen with the appropriate increase of $N_{1}$, indicating the gear pair can realize a certain type of high speed motion.

\section{Discussion on simulation and experimental results}

\subsection{Finite element analysis}

The main structural parameters of the designed high speed curve face gear are shown in Table 2 . In order to reduce the computation, the simplified assembly model is imported into ANSYS for simulation. The material property of gear pair adopts the property of 20CrMnTi. The model was meshed, and the contact area, load and boundary conditions were set. Figure 15 is the simulation of tooth root bending stress of high speed curve face gear when $\theta_{2}=15^{\circ}$.

As can be seen from Figure 15 , when $\theta_{2}=15^{\circ}$, the tooth root bending stress takes the maximum value of 137.66 MPa at $x=2 \mathrm{~mm}$, and it decreases with the increase of the distance from the section of $x=2 \mathrm{~mm}$. The theoretical maximum value of tooth root bending stress is $131.8 \mathrm{MPa}$, and the error between simulation and theory is $4.45 \%$, which is within a reasonable range. The analysis result shows that the simulation variation law is consistent with the theoretical variation law.

Using the above simulation method, the tooth root bending stress in one cycle is simulated, and the maximum value is extracted and compared with the theoretical results, as shown in Figure 16.

As can be seen, the simulated maximum bending stress firstly decreases and then increases, then decreases and finally increases, in accordance with the variation of theoretical maximum bending stress during meshing process. The maximum error is $4.78 \%$, and it is within the error tolerance, indicating that the simulation result is consistent with the theoretical result. And the error mainly comes from the accuracy of mesh generation.

\subsection{Experimental analysis}

The designed high speed curve face gear is machined by 5-axis CNC milling, and the specific properties are shown in Table 3. The measurement of tooth bending stress of this gear pair is based on the principle of electrical measurement of half bridge measuring circuit. According to the working principle of the resistance strain gauge and the force analysis of gear tooth, the measurement of tooth root bending stress was carried out. The experimental platform is shown in Figure 17. 


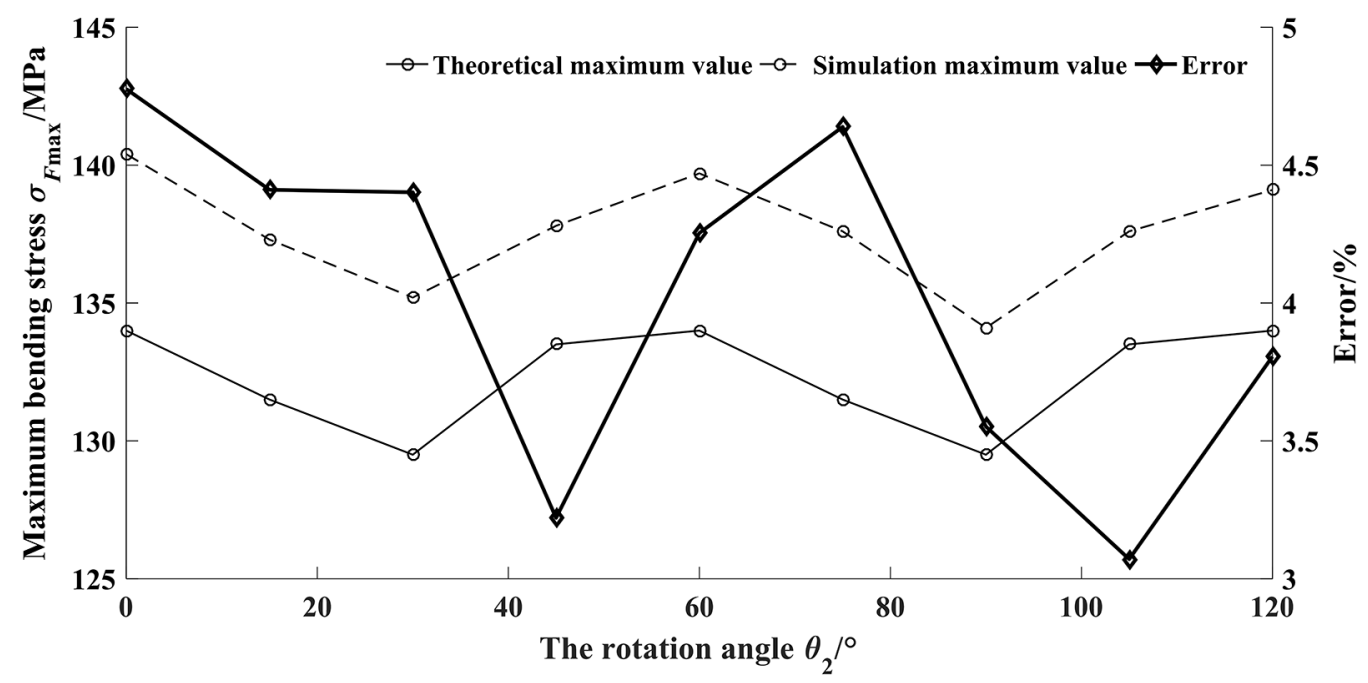

Fig. 16. Theoretical maximum value and simulation maximum value.
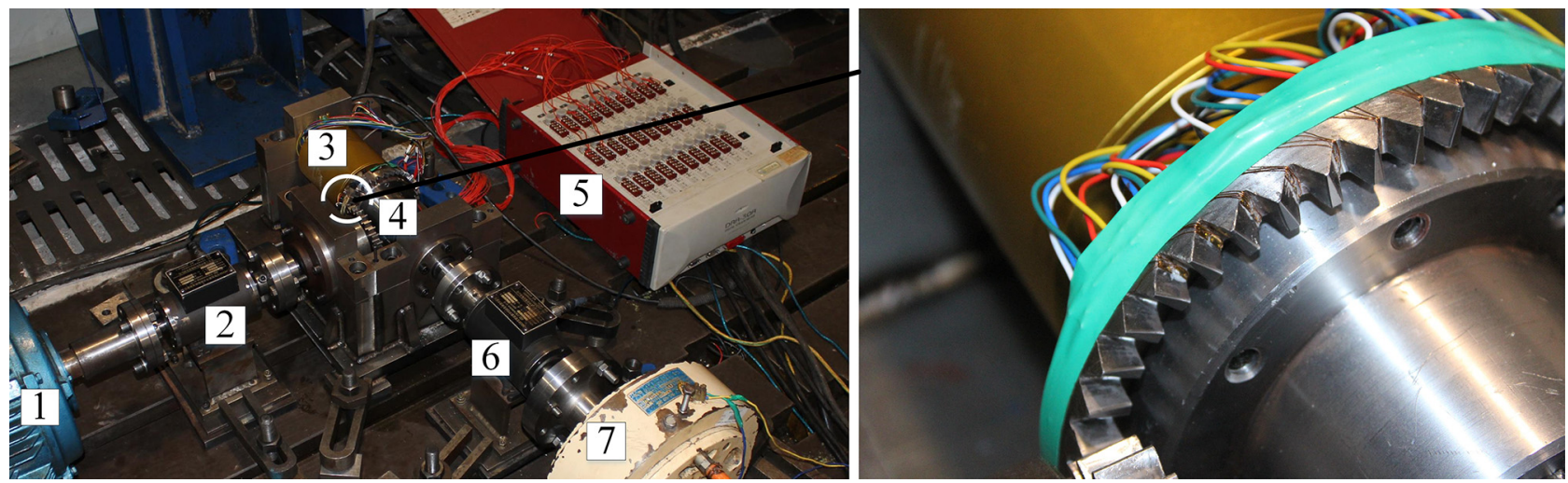

Fig. 17. Measurement of tooth root bending stress.

According to different experimental purposes, strain gauges were pasted at different positions of the tooth root in the direction of tooth width. The strain value of gear tooth root was obtained by DRA-30 multi-channel dynamic and static strain gauge. According to $\sigma_{d}=E \varepsilon_{d}$, the tooth bending stress was obtained, and then the variation of tooth bending stress was determined.

The speed of drive motor is $1500 \mathrm{rpm}$, and the load torque of the driven gear is $100 \mathrm{~N} \cdot \mathrm{m}$, and then the flexural strain in a meshing period was read. After experimental data processing, the tooth bending stress of the driven gear was obtained as shown in Figure 18.

The bending stress of a single tooth in a meshing cycle increases firstly and then decreases. The maximum stress is at the root of tooth 1 , tooth 5 and tooth 9 . The reason is that the tooth bending stress is directly affected by the normal load for the driven gear with size and shape determined.

Taking tooth 5 as an example, the area where it coincides with tooth 4 and tooth 6 is the double-teeth meshing area, and the area where it does not coincide is the single-teeth meshing area. Influenced by single-teeth meshing and double-teeth meshing, the bending stress of

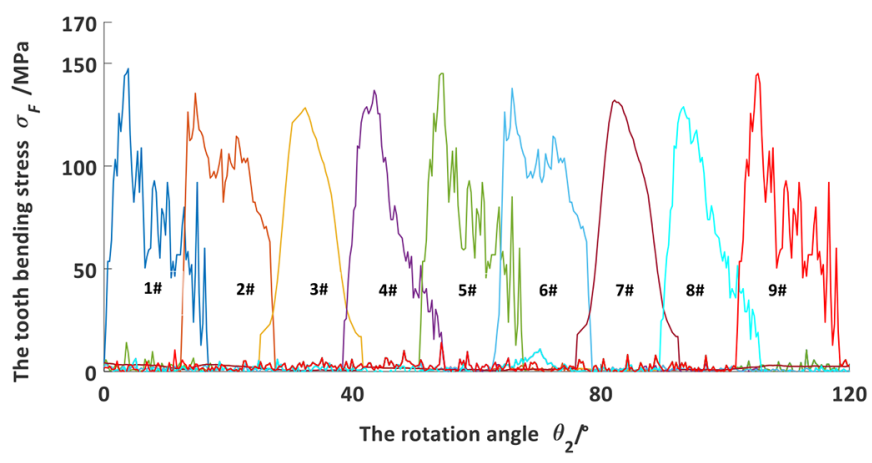

Fig. 18. Measurement results of tooth bending stress.

tooth 5 undergoes three meshing stages, showing a certain waveform variation, and the bending stress reaches the maximum in the single-teeth meshing area. The maximum bending stress value in an engagement period is about150MPa, which is within the acceptable range, indicating the rationality of high speed curve face gear composite transmission. 


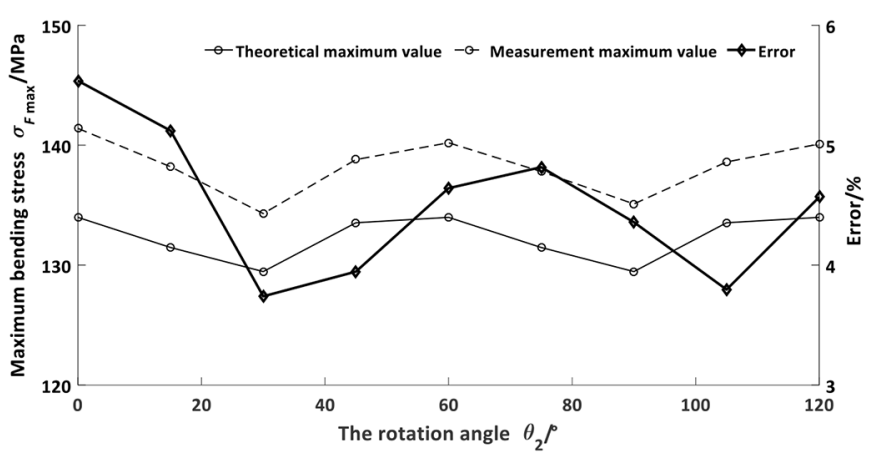

Fig. 19. Theoretical maximum value and measurement maximum value.

The maximum bending stress measured by experiment was extracted and compared with the theoretical maximum bending stress, as shown in Figure 19.

It can be seen that in one cycle, the maximum bending stress measured by experiment firstly decreases and then increases, then decreases and finally increases, in accordance with the variation of theoretical maximum bending stress during meshing process. The maximum error is $5.54 \%$, which is within the error tolerance, indicating that the experimental measurement results are consistent with the theoretical results. And the source of the error is: (a) there is a certain error between the simplified tooth profile and the tooth profile obtained by the conjugate principle; (b) the dynamic load in the composite transmission process of high speed curve face gear has a certain impact on the experimental results.

\section{Conclusions}

The tooth bending stress is of vital importance for transmission performance and load carrying capacity. Based on the study of the tooth bending stress, the following conclusions and limitations can be drawn.

- High speed curve face gear pair can achieve both axial movement and rotation. By discussing the motion mechanism of high speed curve face gear composite transmission, the tooth surface equation of high speed curve face gear is obtained. Tooth force, contact ratio and normal load distribution are calculated and analyzed.

- Based on the force analysis and the normal load distribution, the tooth bending stress was calculated and analyzed, and the results show that the value and fluctuation of maximum bending stress are small during the meshing process. The influence of basic structural parameters on the tooth bending stress was discussed, and the results show that the bending stress is greatly influenced by the stroke $h$ and the order $n_{2}$, while less influenced by the rotational speed $N_{1}$.

- The test platform for high speed curve gear composite transmission was designed and built. The variation of tooth bending stress during the composite transmission was measured. And the rationality of the theoretical research method was verified compared with simulation results and experimental results, which has important guiding significance for the application of high speed curve face gear of composite transmission.

- The detailed dynamics analysis of high speed curve face gear transmission needs to be further studied.

\section{Conflict of Interest}

There is no conflict of interest.

\section{Nomenclature}

$r \quad$ Radius of pinion pitch curve

$r_{2}\left(\theta_{2}\right) \quad$ Position vectors of pitch curve of high speed curve face gear

$R \quad$ Projection radius of pitch curve of high speed curve face gear

$\theta_{1} \quad$ Angular displacement of pinion

$\theta_{2} \quad$ Angular displacement of high speed curve face gear

$s\left(\theta_{2}\right) \quad$ Axial displacement of high speed curve face gear

$\omega_{1}$ and $\omega_{2} \quad$ Angular speeds of the two gears respectively

$v_{1}$ and $v_{2} \quad$ Absolute velocities of meshing point on the pitch curves of two gears respectively

$v_{s 2}$ and $v_{t 2} \quad$ Axial velocity and circumferential velocity of high speed curve face gear respectively

$n \quad$ Normal vector for the meshing point

$a_{s} \quad$ Axial acceleration of high speed curve face gear

$r_{d} \quad$ Pitch radius of generating gear

$r_{d}\left(u_{d}, \theta_{d}\right) \quad$ Tooth surfaceequation of generating gear

$r_{2}\left(u_{d}, \theta_{d}, \theta_{1}\right)$ Tooth surface equation of high speed curve face gear

$f\left(u_{d}, \theta_{d}, \theta_{1}\right) \quad$ Meshing equation between generating gearand high speed curve face gear

$T_{1}$ and $T_{2} \quad$ Torque of pinion and high speed curve face gear respectively

$N_{1}$ and $N_{2} \quad$ Rotational speed of pinion and high speed curve face gear respectively

$F_{n} \quad$ Normal force

$F_{t 1}$ and $F_{r 1} \quad$ Tangential force and radial force of pinion respectively

$F_{t 2}$ and $F_{a 2} \quad$ Tangential force and axial force of high speed curve face gear respectively

$P_{n}$

$\varepsilon\left(\theta_{2}\right)$

Normal pitch of high speed curve face gear Instantaneous contact ratio of gear pair

Addendum height of pinion and high speed curve face gear

Load distribution coefficient

$q$

Tooth width of high speed curve face gear

$c$ and $d \quad$ Inner width and outer width of tooth root section respectively

$h_{x} \quad$ Thickness of tooth root

$l_{x} \quad$ Distance between the fixed end of $X$ and point $P$

$\sigma_{x} \quad$ Tooth bending stress of high speed curve face gear 
$h \quad$ Displacement amplitude of high speed curve face gear

$n_{2} \quad$ Order of high speed curve face gear

$\sigma_{F \max } \quad$ Maximum tooth bending stress of high speed curve face gear

This work was supported by the National Natural Science Foundation of China (No. 51675060), the Chongqing University Graduate Student Research Innovation Project (CYB18023), and the Equipment Pre-Research Project (No. 30105190404).

\section{References}

[1] C.Q. Liu, H. Makino, X.J. Cao, Cam mechanism design, China Machine Press, Beijing, 1997 (in Chinese)

[2] M. Liang, N. Shi, Gear-5-bar combination mechanism's kinematics characteristic simulation, Journal of Xi'an University of Science and Technology 6, 727-730+764 (2013) (in Chinese)

[3] Y.H. Wei, The design of cam-linkage combined mechanisms design for the given locus, Journal of Shaanxi University of Science and Technology 4, 68-71 (2012) (in Chinese)

[4] E. Ottaviano, D. Mundo, G.A. Danieli et al., Numerical and experimental analysis of non-circular gears and cam-follower systems as function generators, Mechanism \& Machine Theory 43, 996-1008 (2008)

[5] H.J. Zou, Q. Zhang, X.W. Wang, Basic characteristic and design method of the composite-mechanism, Machine Design \& Research 22, 16-19 (2006)

[6] C. Lin, H. Gong, N. Nie et al., Geometry design, threedimensional modeling and kinematic analysis of orthogonal fluctuating gear ratio face gear drive, Proceedings of the Institution of Mechanical Engineers, Part C, Journal of Mechanical Engineering Science 227, 779-793 (2013)

[7] C. Lin, L. Zhang, Z.H. Zhang, Transmission theory and tooth surface solution of a new type of non-circular bevel gears, Journal of Mechanical Engineering 50, 66-75 (2014)

[8] C. Lin, Y. Liu, Characteristic analysis and application of composite motion curve-face gear pair, Journal of the Brazilian Society of Mechanical Sciences \& Engineering 38, 1797-1804 (2016)
[9] F.L. Litvin, J.C. Wang, R.B. Bossler et al., Application of face-gear drives in helicopter transmissions, Journal of Mechanical Design 116, 672-676 (1994)

[10] F.L. Litvin, A. Fuentes, C. Zanzi et al., Design, generation, and stress analysis of two versions of geometry of face-gear drives, Mechanism \& Machine Theory 37, 1179-1211 (2002)

[11] F.L. Litvin, I. Gonzalez-Perez, A. Fuentes et al., Design, generation and stress analysis of face-gear drive with helical pinion, Computer Methods in Applied Mechanics and Engineering 194, 3870-3901 (2005)

[12] C. Lin, Y.Q. Yu, Y.N. Hu, Analysis of composite motion law and force of high speed curve-face gear, Journal of Advanced Mechanical Design Systems and Manufacturing 11, 0070 (2017)

[13] G. Lewis, F. Monasa, Large deflections of cantilever beams of non-linear materials of the Ludwick type subjected to an end moment, International Journal of Non-Linear Mechanics 17, 1-6 (1982)

[14] J.D. Andrews, A finite-element analysis of bending stresses induced in external and internal involutes spur gears, Journal of Strain Analysis for Engineering Design 26, 153-163 (1991)

[15] M.A. Hotait, A. Kahraman, T. Nishino, An investigation of root stresses of hypoid gears with misalignments, Journal of Mechanical Design 133, 071006 (2011)

[16] M.A. Hotait, A. Kahraman, Experiments on the relationship between the dynamic transmission error and the dynamic stress factor of spur gear pairs, Mechanism \& Machine Theory 70, 116-128 (2013)

[17] J.W. Ming, A new photoelastic investigation of the dynamic bending stress of spur gears, Journal of Mechanical Design 125, 365-371 (2003)

[18] Z. Chen, M. Zeng, A. Fuentes-Aznar, Geometric design, meshing simulation, and stress analysis of pure rolling rack and pinion mechanisms, Journal of Mechanical Design 142, $1-24(2019)$

[19] T. Nieszporek, R. Gobski, L. Oo, Analysis of the worm wheel toothing accuracy, Tehnicki Vjesnik 24, 993-1000 (2017)

[20] M. Kowalik, M. Rucki, P. Paszta et al., Plastic deformations of measured object surface in contact with undeformable surface of measuring tool, Measurement Science Review 16, $254-259$ (2016)

[21] R. Gobski, E. Ivandi, Analysis of modification of spur gear profile, Tehnicki Vjesnik 25, 643-648 (2018)

[22] R. Gobski, Parametric programming of CNC machine tool, Matec Web of Conferences 94, 07004 (2017)

[23] R. Gobski, A. Szarek, Diagnosis of the operational gear wheel wear, Tehnicki Vjesnik-Technical Gazette 26, 658-661 (2019)

Cite this article as: Y. Yu, C. Lin, Y. Hu, Tooth bending stress analysis of high speed curve face gear of composite transmission, Mechanics \& Industry 22, 20 (2021) 